\title{
PENILAIAN PETANI TERHADAP KINERJA TENAGA HARIAN LEPAS TENAGA BANTU PENYULUH PERTANIAN (THL-TBPP) DALAM PENDAMPINGAN KELOMPOK TANI DI KABUPATEN BANJARNEGARA \\ (Farmers Evaluation To Performances Of Freelance Workers - Agricultural Extension Maid (THL-TBPP) In Mentoring Of Farmers Groups In Banjarnegara District)
}

\author{
Sudarmanto, B. ${ }^{1)}$, Soeharso, ${ }^{2}{ }^{2}$, Tavip Kuntjoro, $\mathbf{H}^{3)}$ \\ ${ }^{1,2)}$ Staf Pengajar Sekolah Tinggi Penyuluhan Pertanian Magelang \\ Jl. Magelang-Kopeng KM 7 Purwosari Tegalrejo Magelang 56192 \\ email: bsudarmanto67@yahoo.com \\ $\left.{ }^{3}\right)$ Fungsional Penyuluh Pertanian Dinas Pertanian Perikanan dan Peternakan Kabupaten \\ Banjarnegara J1.Semampir Kabupaten Banjarnegara
}

Diterima: 13 Mei 2015 Disetujui: 30 Juni 2015

\begin{abstract}
Agricultural Extension as Government Employees spread throughout Indonesia in the last 7 years, its role was helped by Freelance Workers - Agricultural Extension Maid (THL-TBPP). The purpose of research was to determine the performances of THL-TBPP of the farmers evaluation as partners. The research location was in Banjarnegara district, Central Java Province. The samples were farmers, taken by sampling random cluster as performances evaluators of THL-TBPP located in the working area of agricultural extension (WKPP) where farmers were domiciled. The results showed that five variables were in high category (persistence and patience; extension schedule accuracy; mastery and selection of materials; identification and problem-solving strategy advice; development/ farmer group dynamics), the two variables were in medium category (use and selection of extension tools; selection and mastery of technique and method of extension). However, the overall performances of THL-TBPP were included in high category.
\end{abstract}

Keywords: Performances, Freelance Workers - Agricultural Extension Maid, Mentoring

\begin{abstract}
ABSTRAK
Kegiatan Penyuluh Pertanian oleh penyuluh PNS telah dibantu oleh THL TBPP yang tersebar di seluruh Indonesia sedikitnya selama 7 tahun. Tujuan penelitian ini adalah menilai kinerja THL TBPP sebagai pendamping penyuluh pertanian PNS. Penilaian kinerja dilakukan di Kabupaten Banjarnegara, Provinsi Jawa Tengah. Pengambilan data lapang dilakukan terhadap anggota kelompok tani yang berada di wilayah kerja Tenaga Harian Lepas Tenaga Bantu Penyuluh Pertanian (THL-TBPP) dengan lokasi 20 kecamatan se Kabupaten Banjarnegara

Kinerja THL-TBPP dalam pendampingan kelompok tani masuk pada kategori tinggi. Apabila dirinci pada setiap variabel penilaian maka, lima variabel masuk kategori tinggi
\end{abstract}


yaitu: ketekunan dan kesabaran; ketepatan jadwal penyuluhan; penguasaan dan pemilihan materi; identifikasi dan saran strategi pemecahan masalah; dan pengembangan/dinamika kelompok tani), sedangkan dua variabel masuk kategori sedang yaitu: penggunaan dan pemilihan alat bantu penyuluhan serta Pemilihan dan penguasaan teknik dan metode penyuluhan. Kinerja THL-TBPP dalam pendampingan kelompok tani masuk pada katagori tinggi. Apabila dirinci pada setiap variabel penilaian maka, lima variabel masuk katagori tinggi yaitu: ketekunan dan kesabaran; ketepatan jadwal penyuluhan; penguasaan dan pemilihan materi; identifikasi dan saran strategi pemecahan masalah; dan pengembangan/dinamika kelompok tani), sedangkan dua variabel masuk katagori sedang yaitu: penggunaan dan pemilihan alat bantu penyuluhan serta Pemilihan dan penguasaan teknik dan metode penyuluhan

Kata kunci: Kinerja, Tenaga Harian Lepas -Tenaga Bantu Penyuluh Pertanian, Pendampingan

\section{PENDAHULUAN}

\section{A. Latar Belakang}

Jumlah Penyuluh Pertanian utamanya yang berstatus Pegawai Negeri Sipil (PNS) di Indonesia semakin lama terus berkurang. Hal ini dikarenakan banyak Penyuluh Pertanian PNS yang telah memasuki purna bhakti namun belum ada pengangkatan kembali Penyuluh Pertanian di hampir seluruh daerah di Indonesi. Amanat Undang Undang Nomor 16 Tahun 2006 tentang Sistem Penyuluhan Pertanian Perikanan dan Kehutanan (SP3K) bahwa kebutuhan Penyuluh Pertanian minimal adalah satu desa satu penyuluh. Kebutuhan Formasi Penyuluh Pertanian mulai dari pusat sampai desa menurut Pusat Penyuluhan BPPSDMP tahun 2013 berjumlah 69.664 orang, dan hal ini bisa dipenuhi melalui Penyuluh Pertanian PNS, Penyuluh Pertanian Swasta, dan Penyuluh Pertanian Swadaya.

Amanat Undang-Undang juga mengisyaratkan bahwa keberadaan penyuluh masih sangat dibutuhkan oleh masyarakat, apalagi apabila kita ingin mencapai sukses pembangunan pertanian di Indonesia: (1) swasembada dan swasembada berkelanjutan; (2) diversifikasi pangan; (3) peningkatan nilai tambah, daya saing, dan ekspor; serta (4) meningkatkan kesejahteraan petani (Kementan, 2010).

Kebutuhan Penyuluh Pertanian yang mendesak mendorong munculnya kebijakan dari Departemen Pertanian mulai Tahun 2007 untuk mengangkat Tenaga Harian Lepas Tenaga Bantu Penyuluh Pertanian (THL-TBPP) yang dari lulusan SLTA sampai dengan $\mathrm{S} 2$ pertanian (agro komplek). Pengangkatan THL-TBPP angkatan pertama sampai dengan ketiga (tahun 2007-2009) sekitar 26.000 orang (Kementan, 2012).

Kekurangan Penyuluh Pertanian terjadi pula di Kabupaten Banjarnegara, karena menurut BPS Kab. Banjarnegara (2013), dari 20 kecamatan terdiri dari 266 desa dan 12 kelurahan. Jumlah Penyuluh Pertanian PNS hanya 80 orang dan THL TBPP 103 orang, sehingga satu orang penyuluh memiliki wilayah kerja penyuluhan 1 sampai dengan 2 desa. Peran serta THL-TBPP didalam mendampingi pelaku utama dan pelaku usaha sebagai mitra kerja sangat diharapkan. Oleh karena itu perlu dievaluasi kinerja dari THL-TBPP ini dari sisi pelaku utama yang merupakan anggota kelompok tani dan berada di dalam wilayah kerja Penyuluh yang bersangkutan. 


\section{B. Perumusan Masalah}

Rumusan masalah penelitian adalah belum diketahuinya kinerja THL-TBPP di Kabupaten Banjarnegara dalam melakukan pendampingan kelompok tani.

\section{Tujuan Penelitian}

Tujuan penelitian adalah mendeskripsikan kinerja THL-TBPP di Kabupaten Banjarnegara dalam melakukan pendampingan kelompok tani.

\section{Manfaat Penelitian}

Manfaat dari penelitian ini antara lain:

1. Bagi Dinas Pertanian Perikanan dan Peternakan Kabupaten Banjarnegara, sebagai bahan evaluasi keberadaan THL-TBPP sekaligus mendorong peningkatan kinerja agar lebih baik didalam melakukan pendampingan kelompok tani dimasa-masa mendatang.

2. Bagi THL-TBPP sendiri sebagai evaluasi kinerjanya dari pihak stakeholder sehingga dapat memperbaiki diri dari segi media, materi ataupun metode pendekatan yang selama ini dilakukan.

3. Bagi Pemerintah Daerah dan Pusat dapat digunakan sebagai acuan didalam mengambil kebijakan tenaga harian lepas khususnya bidang penyuluhan, untuk diterapkan didalam berbagai dinas atau instansi yang membutuhkan.

\section{MATERI DAN METODE}

\section{A. Materi Penelitian}

Pengambilan data lapang dilakukan terhadap anggota kelompok tani yang berada di wilayah kerja Tenaga Harian Lepas Tenaga Bantu Penyuluh Pertanian (THL-TBPP) dengan lokasi 20 kecamatan se Kabupaten Banjarnegara. Materi kajian berkenaan dengan penilaian anggota kelompok tani tentang kinerja THL-TBPP yang mencakup: (1). Ketekunan dan kesabaran; (2). Ketepatan jadwal penyuluhan; (3). Penguasaan dan pemilihan materi; (4). Penggunaan dan pemilihan alat bantu penyuluhan; (5). Pemilihan dan penguasaan teknik dan metode penyuluhan; (6). Identifikasi dan saran atau strategi pemecahan masalah; dan (7). Pengembangan/ dinamika kelompok tani.

\section{B. Metode Penelitian}

\section{Penetapan responden}

Responden penelitian diambil secara cluster random sampling, dimana petani merupakan anggota kelompok yang berada di wilayah kerja THL-TBPP. Dua kelompok tani pada setiap kecamatan dengan masing-masing 1 petani diambil secara acak, sehingga responden secara keseluruhan 40 orang. Petani terpilih akan menilai kinerja THL-TBPP yang selama ini membina dan mendampingi kelompok tani serta usaha petani yang bersangkutan.

2. Pengumpulan data

Pengumpulan data meliputi: pencatatan, yaitu pengumpulan data sekunder dari sumber terkait; dan wawancara, yaitu pengumpulan data melalui diskusi secara langsung dengan responden menggunakan kuesioner. Kuesioner telah diuji tingkat reliabilitas atau kehandalannya dengan mengukur koreasinya menggunakan Cronbach Alfa $(\alpha)$, dan suatu konstruk atau variabel dikatakan reliabel manakala nilai $\alpha>0,60$ (Nunnally, 1967 dalam Ghozali, 2006). Validitas atau kesahihan kuesioner diukur dengan Korelasi Bivariate (Ghozali, 2006), dan nilai indikator terhadap total skor konstruk signifikan atau valid.

3. Metode analisis 
Data diolah dan dianalisis secara deskriptif kuantitatif. Pendeskrisian dipilah dalam substansi: (1). Ketekunan dan kesabaran; (2). Ketepatan jadwal penyuluhan; (3). Penguasaan dan pemilihan materi; (4). Penggunaan dan pemilihan alat bantu penyuluhan; (5). Pemilihan dan penguasaan teknik penyuluhan; (6). Identifikasi dan saran atau strategi pemecahan masalah; serta (7) Pengembangan dinamika kelompok tani.

Indikator penilaian menggunakan skala linkert yang merupakan respons petani terhadap kinerja THL-TBPP (Abdurrahman, 2012) pada katagori: baik (3); kurang baik (2); dan tidak baik (1); yang digunakan untuk mengasumsikan masing-masing substansi kajian, atau kalau dirata-rata nilai setiap item pertanyaan berada pada kisaran: 1,00 - 1,66 (rendah atau tidak baik); 1,67 - 2,33 (sedang atau kurang baik); dan 2,34 - 3,00 (tinggi atau baik). Total hasil penilaan petani terhadap THL-TBPP merupakan kinerja pendampingan kelompok tani dengan nilai terendah 40 dan tertinggi 120 atau dengan kisaran nilai 40 - 66,66 (rendah atau tidak baik); 66,67 - 93,33 (sedang atau kurang baik); dan 93,34 - 120,00 (tinggi atau baik).

\section{HASIL DAN PEMBAHASAN}

\section{A. Karakteristik THL-TBPP}

Sampai akhir tahun 2013 Penyuluh Pertanian di Kabupaten Banjarnegara berada pada Kelompok Jabatan Fungsional di bawah Dinas Pertanian, Perikanan, dan Peternakan, dan di tingkat kecamatan berada pada Balai Penyuluhan Pertanian. 80 Penyuluh Pertnian PNS dan 103 THLTBPP membina 278 desa dan kelurahan sehingga banyak penyuluh yang wilayah kerjanya meliputi 2 desa/kelurahan.
Keberadaan THL-TBPP di 20 kecamatan dengan jumlah rata-rata 5 orang, meskipun ada kecamatan yang jumlahnya 2 orang dan 10 orang karena dalam pertimbangan luas wilayah binaan dan potensi pertanian di kecamatan yang bersangkutan. Operasional kegiatan THLTBPP berkolaborasi dengan Penyuluh Pertanian PNS yang jumlahnya relatif lebih sedikit.

Usia THL-TBPP bervariasi mulai 28 tahun sampai dengan 54 tahun, dengan jenjang pendidikan formal SLTA $(51,46 \%)$, D3 (18,44\%), dan D4 atau S1 Pertanian/Peternakan/Biologi (30,10\%).

\section{B. Kinerja THL-TBPP}

1. Ketekunan dan kesabaran

THL-TBPP mendampingi petani dan kelompok tani mulai dari perencanaan kegiatan kelompok, identifikasi materi penyuluhan yang dibutuhkan, pengembangan usahatani dan kelompok sampai dengan menggali potensi sumber daya yang ada di kelompokdan desa setempat. Heterogennya faktor internal dan eksternal anggota kelompok ternyata dapat didekati dengan ketekunan dan kesabaran. Petani menilai tingkat ketekunan dan kesabaran petani adalah tinggi (rata-rata 2,9). Hal ini disadari mengingat THL-TBPP rata-rata berasal dari wilayah setempat sehingga dapat memahami kondisi masyarakat/petani diwilayah yang bersangkutan.

2. Ketepatan jadwal penyuluhan

$$
\text { Jadwal penyuluhan yang }
$$

direncanakan bersama antara penyuluh dan kelompok pada sore hari paling banyak (55,0\%), malam hari $32,5 \%$ dan pagi hari atau jam kantor penyuluh (12,5\%). Tingkat kehadiran dan ketepatan waktu kedatangan THL-TBPP pada kegiatan penyuluhan dinilai tinggi $(2,6)$, apabila tidak hadir 
berusaha untuk diganti oleh penyuluh yang lain atau memberitahukan apabila mengalami keterlambatan datang. Ketepatan jadwal dan menepati janji sesuai yang telah disepakati akan meningkatkan kepercayaan dan antusiasme petani terhadap penyuluh.

\section{Penguasaan dan pemilihan materi;}

Rata-rata hasil penilaian petani pada penguasaan materi dan pemilihannya adalah tinggi $(2,92)$. Materi penyuluhan ada yang sudah jauh hari direncanakan terlebih dahulu dan masuk pada programa penyuluhan maupun yang sifatnya insidentil karena adanya kondisi tertentu seperti wabah hama/penyakit, kondisi anaman yang tidak baik, kondisi ekstrim (banjir atau longsor, kemarau panjang,dan lain-lain). Disamping itu petani akan antusias megikuti penyuluhan apabila materi yang disampaikan memang merupakan kebutuhan dan dapat membantu pemecahan permasalahan petani (Mawardi, 2004).

4. Penggunaan dan pemilihan alat bantu penyuluhan

Alat bantu penyuluhan yang paling banyak digunakan melalui media cetak (leaflet, folder, peta singkap ataupun lembar informasi) dan dilakukan secara langsung, sehingga tidak sekedar dibagikan namun ada komunikasi dua arah antara petani dan penyuluh $(72,5 \%)$, Penggunaan media terproyeksi (15\%) baik berupa tayangan power point maupun film, dan secara lisan saja (12,5\%), yang biasanya pada penyuluhan yang bersifat insidentil ataupun diaral usahatani.

Alat bantu yang digunakan THLTBPP dalam penyuluhan telah bervariasi, namun petani menilai penggunaan dan pemilihan alat bantu yang digunakan masih dalam katagori sedang $(2,3)$, hal ini perlu lebih diperhatikan oleh penyuluh karena dari hasil penilaian petani bahwa penggunaan alat bantu memudahkan mereka memahami materi penyuluhan yang diterima.

5. Pemilihan dan penguasaan teknik dan metode penyuluhan

Hasil penilaian petani terhadap pemilihan metode penyuluhan pada katagori sedang $(2,07)$, hal ini karena jarangnya kegiatan penyuluhan melalui sekolah lapang (SL), studi banding. Untuk demonstrasi telah sering dilakukan, namun untuk studi banding dan SL seringkali terkendala oleh biaya. Hal ini diakui baik dari pihak petani maupun penyuluh, oleh karena alternatif penggunaan teknik dan metode penyuluhan perlu lebih dikreasikan serta dikerjasamakan dengan pelaku usaha ataupun instansi terkait lainnya.

Hal tersebut diatas juga selaras dengan pernyataan Padmowihardjo (1997), bahwa dengan megoptimalkan keberadaan beberapa pancaindra akan menaikkan tingkat adopsi dan ingatan dari sasaran terhadap materi yang disampaikan dalam kgiatan penyuluhan.

6. Identifikasi dan saran atau strategi pemecahan masalah

Identifikasi masalah petani dilakukan terutama saat penyusunan Rencana Definitif Kelompok (RDK), Rencana Definitif Kebutuhan Kelompok (RDKK) sampai dengan Progra Penyuluhan dan Rencana Kerja Tahunan Penyuluhan (RKTP). Oleh karena itu penilaian petani pada identifikasi masalah tergolong tinggi $(2,37)$, meskipun dalam strategi pemecahan masalah masih perlu ditingkatkan karena pada katagori sedang (2,32). Strategi pemecahan masalah kadangkala terkendala pada sarana dan prasarana penyuluhan. Oleh sebab itu seperti permasalahan sebelumnya masih perlu terobosan kerjasama dengan instansi terkait dan 
pengusulan fasilitas ke Pemerintah Daerah maupun Kementerian Pertanian.

7. Pengembangan/ dinamika kelompok tani.

Kinerja THL-TBPP dalam membantu mengembangkan kelompok tani serta mendinamiskan kondisi kelompok tergolong tinggi $(2,68)$, meskipun ada beberapa item penilaian yang masih perlu ditingkatkan dalammenggerakkan massa atau anggota kelompok tani untuk pembersihan saluran air, pemberantasan tikus, vaksinasi ND dan lain-lain pada katagori sedang $(2,2)$ serta mendorong kelompok tani/petani dalam pemupukan modal (2,3). Untuk item lainnya seperti menjembatani pencarian sarana produksi, bimbingan usahatani terpadu, menguatkan kelembagaan, memberi motivasi untuk terus meningkatkan kemampuan dalam usahatani dan lain-lain tergolong tinggi.

Secara keseluruhan dari indikator penilaian kinerja THL-TBPP dalam mendampingi kelompok tani masuk dalam katagori tinggi $(2,67)$, artinya disini bahwa keberadaan THL-TBPP sebagai Penyuluh Pertanian yang keberadaannya dapat berkolaborasi dan berdampingan dengan Penyuluh Pertanian PNS. Hal ini berarti bahwa Tugas pokok THL-TBPP mulai dari menyiapkan, melaksanakan dan mengevaluasi kegiatan penyuluhan serta fungsinya mulai dari menyebarkan informasi pembangunan pertanian, membangun kelembagaan petani, sampai dengan memberikan bimbingan dan memecahkan permasalahan petani telah (Departemen Pertanian, 2007) telah dapat dilakukan dengan baik.

\section{KESIMPULAN DAN SARAN}

\section{Kesimpulan}

Kinerja THL-TBPP dalam pendampingan kelompok tani masuk pada katagori tinggi. Apabila dirinci pada setiap variabel penilaian maka, lima variabel masuk katagori tinggi yaitu: ketekunan dan kesabaran; ketepatan jadwal penyuluhan; penguasaan dan pemilihan materi; identifikasi dan saran strategi pemecahan masalah; dan pengembangan/dinamika kelompok tani), sedangkan dua variabel masuk katagori sedang yaitu: penggunaan dan pemilihan alat bantu penyuluhan serta Pemilihan dan penguasaan teknik dan metode penyuluhan.

\section{Saran}

1. Bagi THL-TBPP, Penilaian petani merupakan kondisi nyata di lapangan oleh karena itu hal-hal yang masih dirasa belum optimal perlu terus ditingkatkan terutama pada penggunaan dan pemilihan alat bantu, serta pemilihan dan penguasaan teknik dan metode penyuluhan.

2. Bagi Pemerintah Pusat dan Daerah, kinerja dari THL-TBPP termasuk dalam katagori tinggi dan dilapangan dapat berkolaborasi dengan Penyuluh Pertanian PNS, oleh sebab itu fasilitasi untuk kegiatan penyuluhan dan keberlanjutan program serta halhal yang berkenaan dengan kesejahteraan THL-TBPP juga patut untuk diperjuangkan.

\section{DAFTAR PUSTAKA}

Abdurrahman, M. 2012. Skala Pengukuran dalam Penelitian. http://muksin abdurrahman com/?dl_id=16. Diunduh pada 10-2012. 
BPS Kab. Banjarnegara, 2013. Banjarnegara dalam Angka. http://banjarnegarakab.bps.go.id/ind ex.php?hal=tabel\&id=8. Diunduh pada 19-04-2014.

Departemen Pertanian. 2007. Peraturan Menteri Pertanian Nomor: 37 /OT.140/3/2007 tentang Pedoman Pembinaan Tenaga Harian Lepas (THL) Tenaga Bantu Penyuluh Pertanian.

Ghozali, I. 2006. Aplikasi Program Analisis Multivariate dengan Program SPSS. Semarang: Badan Penerbit Universitas Diponegoro.

Kementerian Pertanian. 2010. Peningkatan Kualitas Program untuk Mewujudkan Revitalisasi Pengembangan Sumber Daya Manusia (SDM) Pertanian. http://www.deptan.go.id/bpsdmp.

Diunduh pada 20-04-2013.

Kementerian Pertanian. 2012. Pedoman Pelaksanaan Pengelolaan Honorarium dan Biaya Operasional Penyuluh (BOP) bagi Tenaga Harian Lepas Tenaga Bantu (THLTB) Penyuluh Pertanian.

Mawardi, S. 2004. Persoalan Penyuluhan di Era Otonomi Daerah. SMERU Newsletter. Jakarta. Desember 2004.

Padmowihardjo, S. 1997. Media Penyuluhan Pertanian. Jakarta: Universitas Terbuka. 